\title{
A Hospitalist Mentoring Program to Sustain Interest in Healthcare Careers in Under-Represented Minority Undergraduates
}

\author{
Lilia Cervantes, $\mathrm{MD}^{1,2^{*}}$, Eugene Chu, MD²,3 Carmella Nogar, $\mathrm{PA}^{2}$, Marisha Burden, $\mathrm{MD}^{1,2}$, Stacy Fischer, $\mathrm{MD}^{2}$, \\ Christian Valtierra, M.Ed ${ }^{4}$, Richard K. Albert, MD ${ }^{1,2}$
}

\begin{abstract}
'Department of Medicine, Denver Health, Denver, Colorado; '2Department of Medicine, University of Colorado School of Medicine, Aurora, Colorado; ${ }^{3}$ Hospital Medicine, Boulder Community Hospital, Boulder, Colorado; ${ }^{4}$ Office of Diversity and Inclusion, University of Colorado Anschutz Medical Campus, Denver, Colorado.
\end{abstract}

BACKGROUND: Ethnic minorities in the United States have decreased access to healthcare and disproportionately high morbidity and mortality. There has been minimal growth in the number of minority physicians despite their important role in reducing health disparities. Underrepresented minority (URM) undergraduate students are $50 \%$ less likely to maintain interest in medical careers.

METHODS: Denver Health and the University of Colorado, Denver enrolled URM students interested in healthcare careers in a year-long, comprehensive program called the Healthcare Interest Program (HIP) that included pairing each student with a hospitalist for mentoring and job shadowing. At the end of the first year of HIP, students were surveyed, and 2 years later they were contacted for follow-up.
RESULTS: Twenty-three students enrolled and all completed the program. Nineteen $(83 \%)$ completed the survey and all "strongly agreed" that participating in HIP expanded their perceptions of what they might accomplish and increased their confidence in their ability to participate in a healthcare profession. Two-year follow-up was available for 21 students (91\%). Twenty (95\%) remained committed to a career in healthcare, 18 (86\%) had graduated, and 6 (29\%) were enrolled in postgraduate healthcare training.

CONCLUSION: The interest of undergraduate minority prehealth students in healthcare careers may be maintained by participation in a multifaceted, year-long mentoring program such as HIP. Journal of Hospital Medicine 2014;9:586-589. (C) 2014 Society of Hospital Medicine
The fraction of the US population identifying themselves as ethnic minorities was $36 \%$ in 2010 and will exceed $50 \%$ by $2050 .{ }^{1,2}$ This has resulted in an increasing gap in healthcare, as minorities have welldocumented disparities in access to healthcare and a disproportionately high morbidity and mortality. ${ }^{3}$ In 2008 , only $12.3 \%$ of US physicians were from underrepresented minority (URM) groups (see Figure in Castillo-Page 4) (ie, those racial and ethnic populations that are underrepresented in the medical profession relative to their numbers in the general population as defined by the American Association of Medical Colleges $\left.{ }^{4,5}\right)$. Diversifying the healthcare workforce may be an effective approach to reducing healthcare disparities, as URM physicians are more likely to choose primary care specialties, ${ }^{6}$ work in underserved communities with socioeconomic or racial mixes similar to their own, thereby increasing access to care, ${ }^{6-8}$ increasing minority patient satisfaction, and improving the quality of care received by minorities. ${ }^{9-11}$

\footnotetext{
*Address for correspondence and reprint requests: Lilia Cervantes, MD, Denver Health, 660 Bannock St., MC 4000, Denver, CO 80204; Telephone: 303-602-5075; Fax: 303-602-5056;

E-mail: lilia.cervantes@dhha.org

Additional Supporting Information may be found in the online version of this article.

Received: January 31, 2014; Revised: May 8, 2014; Accepted: May 13, 2014

2014 Society of Hospital Medicine DOI 10.1002/jhm.2218

Published online in Wiley Online Library (Wileyonlinelibrary.com).
}

The number of URM students attending medical school is slowly increasing, but in 2011 , only $15 \%$ of the matriculating medical school students were URMs (see Figure 12 and Table 10 in Castillo-Page ${ }^{12}$ ), and medical schools actively compete for this limited number of applicants. To increase the pool of qualified candidates, more URM students need to graduate college and pursue postgraduate healthcare training. ${ }^{12}$

URM undergraduate freshmen with intentions to enter medical school are $50 \%$ less likely to apply to medical school by the time they are seniors than their non-Latino, white, and Asian counterparts. ${ }^{13}$ Higher attrition rates have been linked to students having negative experiences in the basic science courses and with a lack of role models and exposure to careers in healthcare. ${ }^{13-16}$ We developed a hospitalist-led mentoring program that was focused on overcoming these perceived limitations. This report describes the program and follow-up data from our first year cohort documenting its success.

\section{METHODS}

The Healthcare Interest Program (HIP) was developed by 2 hospitalists (L. C., E. C.) and a physician's assistant (C. N.) who worked at Denver Health (DH), a university-affiliated public hospital. We worked in conjunction with the chief diversity officer of the University of Colorado, Denver (UCD), primarily a commuter university in metropolitan Denver, where URMs composed $51 \%$ of the 2011 freshmen class. 
TABLE 1. Healthcare Interest Program Components

\begin{tabular}{|c|c|}
\hline Component & Goal \\
\hline \multicolumn{2}{|l|}{ Clinical shadowing } \\
\hline $\begin{array}{l}\text { Student meets with their mentor and/or with other healthcare providers (eg, pharmacist, nurse) } 4 \text { hours } \\
\text { per day, } 1 \text { or } 2 \text { times per month. }\end{array}$ & $\begin{array}{l}\text { Expose students to various healthcare careers and to care for underserved } \\
\text { patients. }\end{array}$ \\
\hline \multicolumn{2}{|l|}{ Mentoring } \\
\hline $\begin{array}{l}\text { Student meets with their mentor for life coaching, career counseling, and to learn interviewing techni- } \\
\text { ques } 4 \text { hours per month }\end{array}$ & $\begin{array}{l}\text { Expand ideas of opportunity, address barriers or concerns before they affect } \\
\text { grades, write letter of recommendation }\end{array}$ \\
\hline \multicolumn{2}{|l|}{ Books to Bedside lectures } \\
\hline $\begin{array}{l}\text { One lecture per month designed to integrate clinical medicine with the undergraduate basic sciences. } \\
\text { Sample lectures include: "The Physics of Electrocardiograms" and "The Biochemistry of Diabetic } \\
\text { Ketoacidosis" }\end{array}$ & Improve the undergraduate experience in the basic science courses \\
\hline \multicolumn{2}{|l|}{ Book club } \\
\hline $\begin{array}{l}\text { Group discussions of books selected for their focus on healthcare disparities and cultural diversity; } 2 \text { or } 3 \\
\text { books per year (eg, The Spirit Catches You and You Fall Down by Ann Fadiman, Just Like Us by Helen } \\
\text { Thorpe) }\end{array}$ & $\begin{array}{l}\text { Socialize, begin to understand and discuss health disparities and caring for } \\
\text { the underserved. }\end{array}$ \\
\hline \multicolumn{2}{|l|}{ Diversity lectures } \\
\hline $\begin{array}{l}\text { Three speakers per term, each discussing different aspects of health disparities research being con- } \\
\text { ducted in the Denver metropolitan area }\end{array}$ & $\begin{array}{l}\text { Understand the disparities affecting the students' communities. Inspire inter- } \\
\text { est in becoming involved with research. }\end{array}$ \\
\hline \multicolumn{2}{|l|}{ Social events } \\
\hline $\begin{array}{l}\text { Kickoff, winter, and end-of-year gatherings } \\
\text { Journaling and reflection essay }\end{array}$ & Socializing, peer group support \\
\hline Summary of hospital experience with mentor and thoughts regarding healthcare career goals and plans. & Formalize career goals \\
\hline
\end{tabular}

We reviewed articles describing mentoring programs for undergraduate students, and by consensus, designed a 7-component program, each of which was intended to address a specific barrier identified in the literature as possibly contributing to reduced interest of minority students in pursuing medical careers (Table 1). ${ }^{13-16}$

During the 2009 to 2010 academic year, information about the program, together with an application, was e-mailed to all students at UCD who selfidentified as having interest in healthcare careers. This information was also distributed at all prehealth clubs and gatherings (ie, to students expressing interest in graduate and professional programs in healthcarerelated fields). All sophomore and junior students who submitted an application and had grade point averages $(\mathrm{GPA}) \geq 2.8$ were interviewed by the program director. Twenty-three students were selected on the basis of their GPAs (attempting to include those with a range of GPAs), interviews, and the essays prepared as part of their applications.

An e-mail soliciting mentors was sent to all hospitalists physicians and midlevels working at $\mathrm{DH} ; 25 / 30$ volunteered, and 20 were selected on the basis of their gender (as mentors were matched to students based on gender). The HIP director met with the mentors in person to introduce the program and its goals. All mentors had been practicing hospital medicine for $\leq 10$ years after their training, and all but 3 were nonLatino white. Each student accepted into the program was paired with a hospitalist who served as their mentor for the year.

The mentors were instructed in life coaching in both e-mails and individual discussions. Every 2 or 3 months each hospitalist was contacted by e-mail to see if questions or problems had arisen and to emphasize the need to meet with their mentees monthly.

Students filled out a written survey after each Books-to-Bedside (described in Table 1) discussion. The HIP director met with each student for at least 1 hour per semester and gathered feedback regarding mentor-mentee success, shadowing experience, and the quality of the book club. At the end of the academic year, students completed a written, anonymous survey assessing their impressions of the program and their intentions of pursuing additional training in healthcare careers (Table 2). We used descriptive statistics to analyze the data including frequencies and mean tests.

Two years after completing the program, each student was contacted via e-mail and/or phone to determine whether they were still pursuing healthcare careers.

\section{RESULTS}

Twenty-three students were accepted into the program (14 female, 9 male, mean age 19 [standard deviation \pm 1$]$ ). Their GPAs ranged from 2.8 to 4.0. Eleven $(48 \%)$ were the first in their family to attend college, $6(26 \%)$ indicated that English was not their primary language, and $16(70 \%)$ were working while attending school. All 23 students stayed in the HIP program for the full academic year.

Nineteen of the 23 students $(83 \%)$ completed the survey at the end of the year. Of these, $19(100 \%)$ "strongly agreed" that the HIP expanded their perceptions of what they might accomplish and increased their confidence in being able to succeed in a 
TABLE 2. End-of-Program Survey

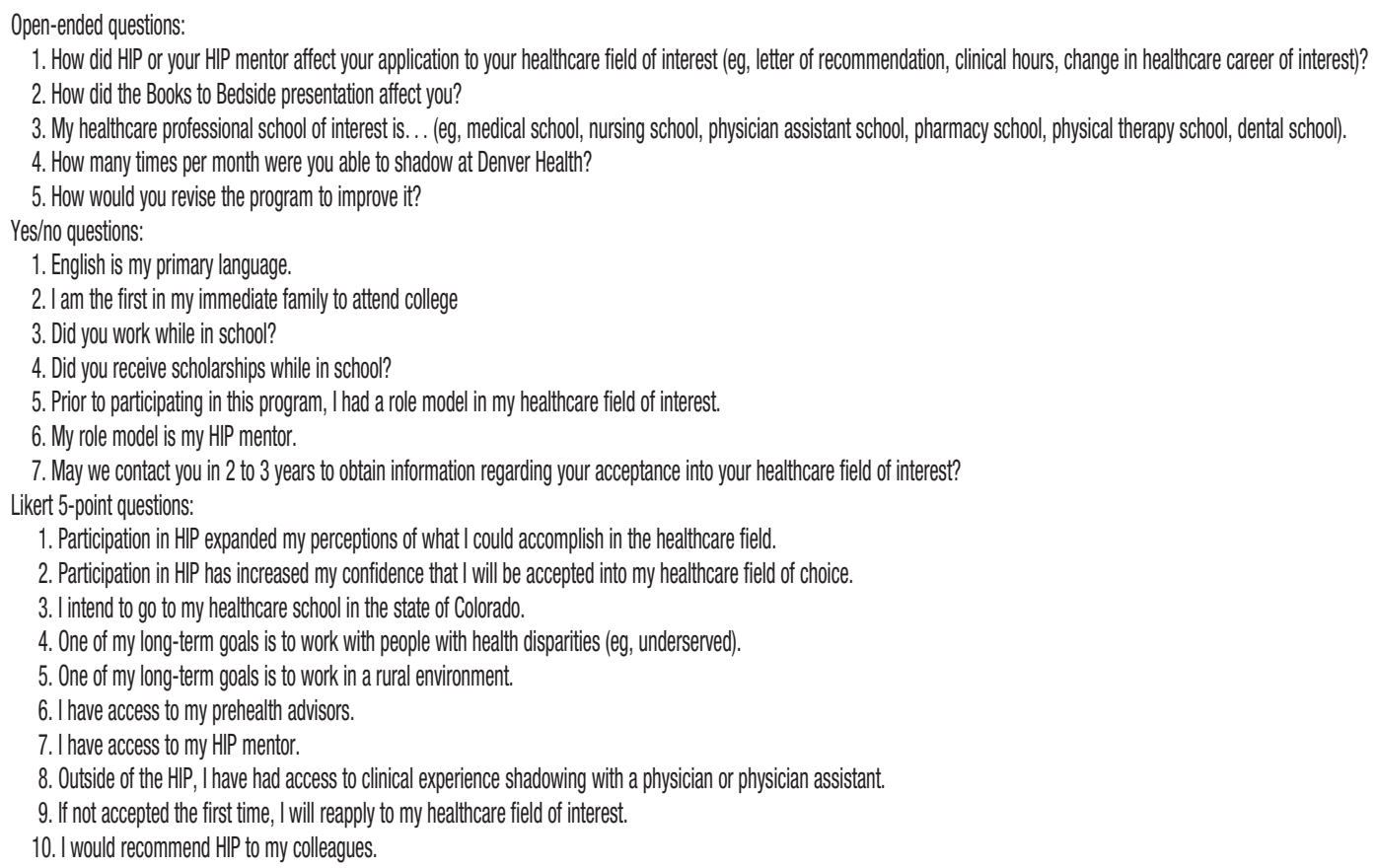

NOTE: Abbreviations: HIP, Healthcare Interest Program.

healthcare profession. All $19(100 \%)$ stated that they hoped to care for underserved minority patients in the future. Sixteen $(84 \%)$ strongly agreed that their role model in life was their HIP mentor. These findings suggest that many of the HIP components successfully accomplished their goals (Table 1).

Two-year follow-up was available for 21 of the 23 students (91\%). Twenty (95\%) remained committed to a career in healthcare, $18(86 \%)$ had graduated college, $6(29 \%)$ were enrolled in graduate training in the healthcare professions ( 2 in medical school, 1 in nursing school, and 3 in a master's programs in public health, counseling, and medical science, respectively), and $9(43 \%)$ were in the process of applying to postgraduate healthcare training programs (7 to medical school, 1 to dental school, and 1 to nursing school, respectively). Five students were preparing to take the Medical College Admissions Test, and 7 were working at various jobs in the healthcare field (eg, phlebotomists, certified nurse assistants, research assistants). Of the 16 students who expressed an interest in attending medical school at the beginning of the program, $15(94 \%)$ maintained that interest.

\section{DISCUSSION}

HIP was extremely well-received by the participating students, the majority graduated college and remained committed to a career in healthcare, and $29 \%$ were enrolled in postgraduate training in healthcare professions 2 years after graduation.
The $86 \%$ graduation rate that we observed compares highly favorably to the UCD campus-wide graduation rates for minority students of $12.5 \%$ at 4 years and $30.8 \%$ at 5 years. Although there may be selection bias in the students participating in HIP, the extremely high graduation rate is consistent with HIP meeting 1 or more of its stated objectives.

Many universities have prehealthcare pipeline programs that are designed to provide short-term summer medical experiences, research opportunities, and assistance with the Medical College Admissions Test. ${ }^{17-19}$ We believe, however, that several aspects of our program are unique. First, we designed HIP to be year-long, rather than a summertime program. Continuing the mentoring and life coaching throughout the year may allow stronger relationships to develop between the mentor and the student. In addition, ongoing studentmentor interactions during the time when a student may be encountering problems with their undergraduate basic science courses may be beneficial. Second, the Books-to-Bedside lectures series, which was designed to link the students' basic science training with clinical medicine, has not previously been described and may contribute to a higher rate of completion of their basic science training. Third, those aspects of the program resulting in increased peer interactions (eg, book club discussions, diversity lectures, and social gatherings) provided an important venue for students with similar interests to interact, an opportunity that is limited at UCD as it is primarily a commuter university. 
A number of lessons were learned during the first year of the program. First, a program such as ours must include rigorous evaluation from the start to make a case for support to the university and key stakeholders. With this in mind, it is possible to obtain funding and ensure long-term sustainability. Second, by involving UCD's chief diversity officer in the development, the program fostered a strong partnership between DH and UCD and facilitated growing the program. Third, the hospitalists who attended the diversity-training aspects of the program stated through informal feedback that they felt better equipped to care for the underserved and felt that providing mentorship increased their personal job satisfaction. Fourth, the students requested more opportunities for them to participate in health disparities research and in shadowing in subspecialties in addition to internal medicine. In response to this feedback, we now offer research opportunities, lectures on health disparities research, and interactions with community leaders working in improving healthcare for the underserved.

Although influencing the graduation rate from graduate level schooling is beyond the scope of HIP, we can conclude that the large majority of students participating in HIP maintained their interest in the healthcare professions, graduated college, and that many went on to postgraduate healthcare training. The data we present pertain to the cohort of students in the first year of the HIP. As the program matures, we will continue to evaluate the long-term outcomes of our students and hospitalist mentors. This may provide opportunities for other academic hospitalists to replicate our program in their own communities.

Disclosure: The authors report no conflicts of interest.

\section{References}

1. United States Census Bureau. An older and more diverse nation by midcentury. Available at: https://www.census.gov/newsroom/releases/ archives/population/cb08-123.html. Accessed February 28, 2013.

2. United States Census Bureau. State and county quick facts. Available at: http://quickfacts.census.gov/qfd/states/00000.html. Accessed February 28,2013
3. Centers for Disease Control and Prevention. Surveillance of health status in minority communities-racial and ethnic approaches to community health across the U.S. (REACH US) risk factor survey, United States, 2009. Available at: http://cdc.gov/mmwr/preview/mmwrhtml/ ss6006a1.htm. Accessed February 28, 2013.

4. Castillo-Page L. Association of American Medical Colleges. Diversity in the physician workforce: facts and figures 2010. Available at: https://members.aamc.org/eweb/upload/Diversity\%20in \%20the \%20 Physician \%20Workforce\%20Facts\%20and\%20Figures\%202010.pdf. Accessed April 29, 2014.

5. Association of American Medical Colleges Executive Committee. The status of the new AAMC definition of "underrepresented in medicine" following the Supreme Court's decision in Grutter. Available at: https://www.aamc.org/download/54278/data/urm.pdf. Accessed May $25,2014$.

6. Smart DR. Physician Characteristics and Distribution in the US. 2013 ed. Chicago, IL: American Medical Association; 2013.

7. Komaromy M, Grumbach K, Drake M, et al. The role of black and Hispanic physicians in providing health care for underserved populations. N Engl J Med. 1996;334:1305-1310.

8. Walker KO, Moreno G, Grumbach K. The association among specialty, race, ethnicity, and practice location among California physicians in diverse Specialties. J Natl Med Assoc. 2012;104:46-52.

9. Saha S, Komaromy M, Koepsell TD, Blindman AB, Patient-physician racial concordance and the perceived quality and use of health care. Arch Intern Med. 1999;159:997-1004.

10. LaVeist TA, Carroll T. Race of physician and satisfaction with care among African-American patients. J Natl Med Assoc. 2002;94:937943.

11. U.S. Department of Health and Human Services Health Resources and Services Administration Bureau of Health Professions. The rational for diversity in health professions: a review of the evidence. 2006. Available at: http://bhpr.hrsa.gov/healthworkforce/reports/ diversityreviewevidence.pdf. Accessed March 30, 2014.

12. Castillo-Page L. Association of American Medical Colleges. Diversity in medical education: facts and figures 2012. Available at: https:// members.aamc.org/eweb/upload/Diversity\%20in\%20Medical\%20Ed ucation $\% 20$ Facts $\% 20$ and $\% 20$ Figures $\% 202012$.pdf. Accessed February $28,2013$.

13. Barr DA, Gonzalez ME, Wanat SF. The leaky pipeline: factors associated with early decline in interest in premedical studies among underrepresented minority undergraduate students. Acad Med. 2008;83: 503-511.

14. Johnson J, Bozeman B. Perspective: adopting an asset bundles model to support and advance minority students' careers in academic medicine and the scientific pipeline. Acad Med. 2012;87:1488-1495.

15. Thomas B, Manusov EG, Wang A, Livingston $\mathrm{H}$. Contributors of black men's success in admission to and graduation from medical school. Acad Med. 2011;86:892-900.

16. Lovecchio K, Dundes L. Premed survival: understanding the culling process in premedical undergraduate education. Acad Med. 2002;77: 719-724.

17. Afghani B, Santos R, Angulo M, Muratori W. A novel enrichment program using cascading mentorship to increase diversity in the health care professions. Acad Med. 2013;88:1232-1238.

18. Keith L, Hollar D. A social and academic enrichment program promotes medical school matriculation and graduation for disadvantaged students. Educ Health. 2012;25:55-63.

19. Parrish AR, Daniels DE, Hester KR, Colenda CC. Addressing medical school diversity through an undergraduate partnership at Texas A\&M Health Science Center: a blueprint for success. Acad Med. 2008;83:512-515. 